\title{
Gold and Silver Bimetallic Core-shell Nanoparticles with a Polydopamine Interface as an Ideal Catalytic Nanosystem
}

\section{İdeal bir Katalitik Nanosistem olarak Polidopamin Arayüzlü Altnn ve Gümüş Bimetalik Çekirdek-Kabuk Nanopartiküller}

\author{
Aslı Yılmaz ${ }^{1,20}$ \\ ${ }^{1}$ Department of Molecular Biology and Genetics, Ataturk University, Erzurum, Turkey. \\ ²East Anatolia High Technology Application and Research Center (DAYTAM), Ataturk University, Erzurum, Turkey.
}

\section{ABSTRACT}

\begin{abstract}
Core-shell nanoparticle systems with their flexible and unique properties have been employed in various applications
especially in catalytic conversion. However, the simple, low-cost, and novel strategies to prepare these nanosystems are still limited and the efficient core-shell nanostructures are highly demanded. In this study, I propose the production of the core-shell bimetallic nanosystem of gold and silver through a thin layer of polydopamine (PDOP). The PDOP layer as interphase provided efficient performance as a reducing and stabilizing agent. The fabrication of the bimetallic core-shell system was confirmed via electron microscope images and UV-vis absorption spectra. The catalytic activity tests, the reduction of 4-nitrophenol (4-NP) to 4-aminophenol (4-AP), of the nanostructures indicated that the emergence of the core-shell system dramatically enhanced the progress of the reaction. It was also noticed that silver reduction time has a significant effect on the catalytic performances of the proposed nanosystem. Total conversion of 4-NP to 4-AP was observed within only 20 min for the case of 60 min of silver reduction time.
\end{abstract}

\section{Key Words}

Bimetallic nanoparticles, core-shell nanoparticles, polydopamine, catalytic conversion, reduction of 4-nitrophenol

\section{öz}

\footnotetext{
ekirdek-kabuk nanopartikül sistemler esnek ve sıradışı özellikleri ile başta katalitik dönüşüm olmak üzere farklı alanlarda kullanılmaktadır. Fakat, bu nanosistemleri üretmek için basit, düşük maliyetli ve yenilikçi stratejiler sınırlı sayıda olup, etkin çekirdek-kabuk nanoyapılar yüksek oranda talep görmektedir. Bu çalışmada ince bir polidopamin (PDOP) tabakası ile oluşturulan bimetalik altın ve gümüş çekirdek-kabuk nanosistemin üretimini önermekteyim. PDOP tabakası bir ara tabaka olarak indirgeme ve stabilize ajan olarak etkin bir performans sunmuştur. Bimetalik çekirdek-kabuk sistemin üretimi elektron mikroskop görüntüleri ve UV-vis absorpsiyon spektrası ile doğrulanmıştır. Nanoyapıların katalitik aktivite testleri, 4-nitrofenolün (4-NP) 4-aminofenole (4-AP) indirgenmesi, çekirdek-kabuk sisteminin tepkimenin ilerlemesini arttırdığı gösterilmiştir. Ayrıca, gümüş indirgeme süresinin önerilen nanosistemin katalitik performansı üzerinde önemli etkiye sahip olduğu gözlenmiştir. 60 dakika gümüş indirgeme süresi için 4-NP'nin 4-AP'ye tamamen dönüşümünün sadece 20 dakikada gerçekleştiği görülmüştür.
}

\section{Anahtar Kelimeler}

Bimetalik nanopartiküller, çekirdek-kabuk nanopartiküller, polidopamin, katalitik dönüşüm, 4-nitrofenol indirgenmesi.

Article History: Received: May 18, 2020; Revised: Jan 21, 2021; Accepted: May 4, 2021; Available Online: Jun 10, 2021.

DOI: https://doi.org/10.15671/hibc.739446

Correspondence to: A. Yılmaz, Department of Molecular Biology and Genetics, Ataturk University, Erzurum, Turkey

E-Mail: asliozdilek@gmail.com 


\section{INTRODUCTION}

$\mathrm{n}$ recent years, due to the increase in better understanding in nanoparticle (NP) synthesis and properties, their employment in various applications especially in catalytic conversion has increased remarkably [1-3]. In catalytic conversion, the activation energy is reduced and thus the rate of the reaction is enhanced with an increased yield of the desired products. Therefore, it is highly desired to prepare robust NP systems with high catalytic activity, stability, and different properties [4].

In the last two decades, core-shell nanoparticle systems with their unique properties have been employed in several applications including sensing, optoelectronic devices and, catalytic conversion. In general, core-shell nanoparticles considered as composite nanomaterials that contain the same or different inner and outer layer material as core and shell, respectively. [5]. Recently, core-shell nanostructures have attracted remarkable interest due to their versatile compositions and relevant extraordinary characteristics. The combination of core and shell materials in different morphologies results in highly functional materials with flexible properties [6]. By manipulating several parameters such as the material of core or shell, the morphology and thickness of each layer, the characteristics of the core-shell nanosystems can be modified accordingly. With these modifications, in comparison to the single core or shell material, core-shell nanosystems represent distinctive properties. Core-shell nanostructures with their extraordinary properties can be employed in a various applications including optical devices, energy storage materials, bioimaging systems, and catalytic processes [5-7]. In comparison to monometallic nanostructures, bimetallic nanostructures usually exhibit unique catalytic properties [6]. These phenomena are basically attributed to the synergistic effect of multi-metals. Despite the progress in the synthesis of bimetallic core-shell nanosystems, simple, low-cost, and novel protocols are highly demanded to produce efficient nanostructures. In this study, I propose bimetallic core-shell nanoparticles of gold and silver as an ideal catalytic system. For this, firstly citrate-stabilized gold nanoparticles (AuNPs) were prepared and a thin layer of bioinspired polydopamine (PDOP) was deposited onto the nanoparticles via oxidative polymerization of dopamine. Herein, PDOP has an essential role in the production of the core-shell nanosystem. Having numerous imine, catechol, and amine functional groups, the PDOP layer provides extraordinary performance in the reduction of silver ions and adsorption of the silver nanostructures as reduction agent and stabilizer, respectively $[8,9]$. Afterward, the PDOP modified AuNPs (AuNP@PDOP) were decorated with a thin layer of silver nanoparticles (AgNPs) simply by immersing them into $\mathrm{AgNO}_{3}$ containing solution. The AgNPs coated AuNP@PDOP (AuNP@PDOP@AgNP) bimetallic core-shell nanosystem was tested as a catalytic system in the reduction of 4-nitrophenol (4-NP) to 4-aminophenol (4-AP). In our previous study, the core-shell nanosystem exhibited unique performance as surface-enhanced Raman spectroscopy (SERS) platform [10]. In this study, I detected that significant progress in the catalytic performance of nanostructure was attained with the emergence of a coreshell system. It was also observed that the silver deposition time is the dominant parameter that determines the catalytic activity of the proposed core-shell nanosystem.

\section{Materials and Methods}

\section{Materials}

All the materials were supplied from Sigma-Aldrich and used directly without any further procedure.

\section{Synthesis of NPs and characterization}

In this study, I aimed to determine the catalytic activity of different NP systems including citrate stabilized-AuNPs, AuNP@PDOP, and the core-shell NP system of AuNP@ PDOP@AgNP for different silver reduction times. In this respect, firstly, AuNPs were prepared through a wellknown citrate reduction method with some modifications according to our earlier reports [11-13]. Briefly, $50 \mathrm{~mL}$ of $0.001 \mathrm{M}$ chloroauric acid was heated to boiling point and then $1.65 \mathrm{~mL}$ of $0.1 \mathrm{M}$ tri-sodium citrate solution was rapidly added to this solution under vigorous magnetic stirring (1400 rpm). The heater was turned off and the AuNPs in pinkish-red color were stored at $4{ }^{\circ} \mathrm{C}$ in the dark until the next usage.

For the fabrication of AuNP@PDOP NP system, the oxidative polymerization of dopamine was employed similar to our earlier studies [10, 14]. $2 \mathrm{~mL}$ of as-prepared AuNPs (200 ppm) was added to $10 \mathrm{~mL}$ dopamine solution (0.4 mg/ $\mathrm{mL}$ ) in Tris-buffer (0.01 M) at $\mathrm{pH}$ : 8.5. The resultant dispersion was mixed gently at room temperature for $2 \mathrm{~h}$. The oxidative polymerization was confirmed via by naked-eye through the gradual color change from pinkish-red to grey. After the polymerization procedure, to remove the PDOP residue and impurities, the dispersion was centrifuged at 15,000 rpm for 20 min. AuNP@PDOP NP dispersion was stored at $4{ }^{\circ} \mathrm{C}$ in the dark until the next usage. 
The reduction of silver ions onto the AuNP@PDOP NPs was conducted through mixing AuNP@PDOP NP dispersion with the $\mathrm{AgNO}_{3}$ solution. For this, briefly, $5 \mathrm{~mL}$ of AuNP@PDOP NP dispersion (200 ppm) was added to 5 $\mathrm{mL}$ of $\mathrm{AgNO}_{3}$ solution (0.01 M) and gently mixed for different reduction time to fabricate AuNP@PDOP@nAgNP NP system (Herein, $n$ stands for silver ion reduction time in $\min )$.

The plasmonic and morphological evaluation of each NP system was investigated in detail by UV-vis absorption spectra (Shimadzu UV-3600 Plus UV-vis-near-infrared (NIR) spectrophotometer) and transmission electron microscopy (TEM, Hitachi HighTech HT7700 and, and FEI Talos F200X) with an energy-dispersive X-ray spectrometer (EDAX), respectively.

\section{Catalytic activity tests of NPs}

In catalytic activity tests, I employed citrate stabilizedAuNPs, AuNP@PDOP, and AuNP@PDOP@nAgNP in the reduction of 4-NP to 4-AP. All catalytic experiments were performed in daylight. In the reduction of 4-NP tests, 1 $\mu \mathrm{g}$ NP containing dispersion was added to $3 \mathrm{~mL}$ solution with a final concentration of $1 \times 10^{-4} \mathrm{M} 4-\mathrm{NP}$ and $0.033 \mathrm{M}$ $\mathrm{NaBH}_{4}$. The reduction of 4-NP was monitored through the absorbance spectra of the relevant system in the wavelength range of $250-800 \mathrm{~nm}$

\section{Results and Discussions}

In this study, I aimed to determine the catalytic activity core/shell bimetallic NP system containing AuNP and AgNP as core and shell material, respectively. Herein, the PDOP layer was employed as an interface between metallic NPs not only as a reduction agent but also as a stabilizing agent $[10,13,15-17]$. In the first part, NP systems were synthesized through the proper methods. Figure 1 summarizes the UV-vis absorption spectra of AuNPs, AuNP@PDOP, and AuNP@PDOP@nAgNP for different silver reduction times. Citrate stabilized-AuNPs exhibited sharp absorption maxima at $518 \mathrm{~nm}$ which indicates the presence of NPs in spherical morphology with the average size of $18 \mathrm{~nm}$ (Figure 2a) [13]. A noticeable red-shift (8 nm) was observed in the absorption maxima of the AuNP@PDOP

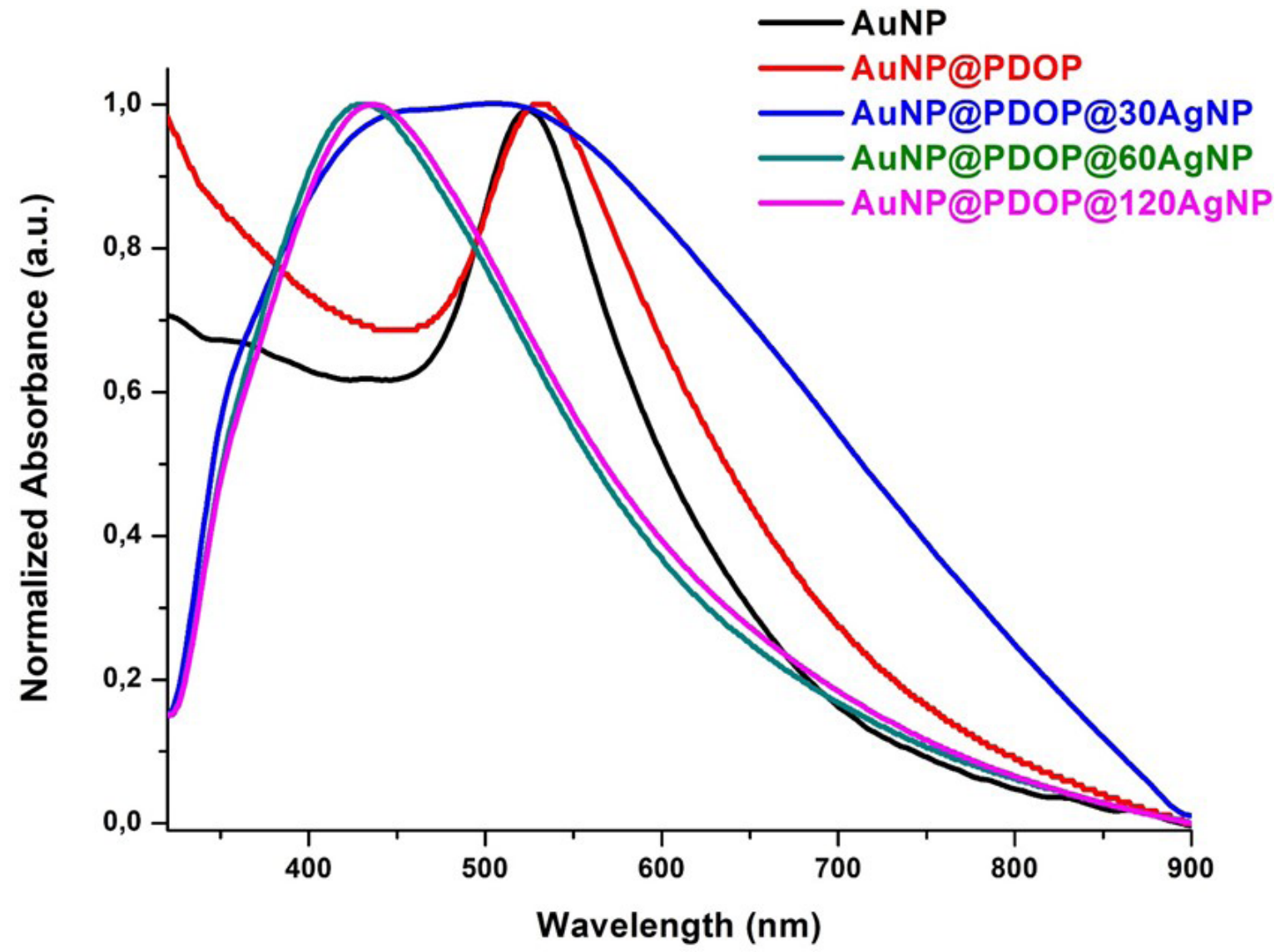

Figure 1. UV-vis absorption spectra of NP systems. 

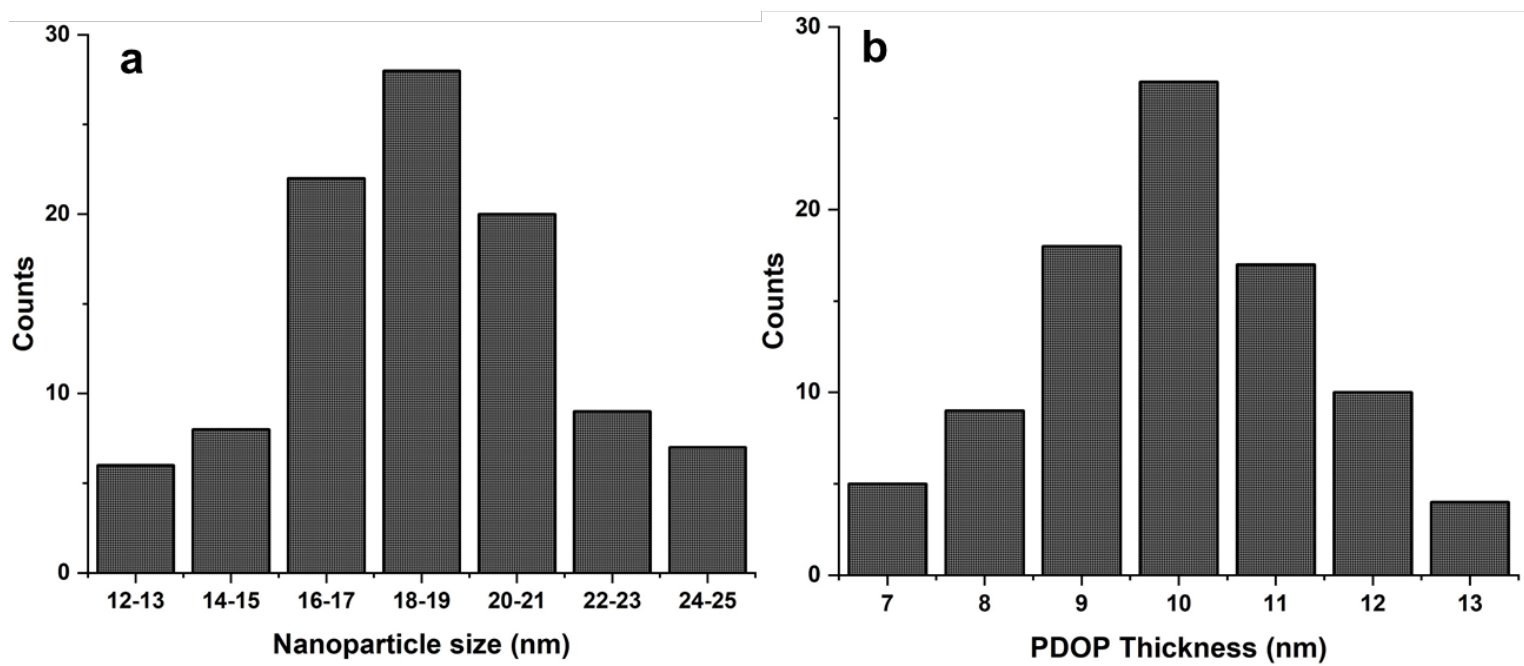

Figure 2. Histograms of AuNP size distributions (a) and PDOP thickness (b) onto the AuNPs. At least 100 measurements were collected from the random NPs or sites.

NPs after the addition of the PDOP layer. This issue may be attributed to the change in dielectric constants of the NP system because of the PDOP layer deposition. When AuNP@PDOP NPs were mixed with the $\mathrm{AgNO}_{3}$ solution, the immediate color change was detected by naked-eye. This experimental observation was furtherly supported by the UV-vis absorption spectra. For the case of lowest silver reduction time (30 min), a dramatic change was observed with a broad shoulder ranging from 400 to $575 \mathrm{~nm}$ indicating the emergence of AgNPs onto the AuNP@PDOP NPs. PDOP with its numerous functional groups including catechol, amine, and imine could reduce metal ions without the employment of any reductive agent [8-10, 13, 15, 17, 18]. The higher silver reduction time also led to their higher reduction and fabrication of AgNPs. For the cases of 60 and 120 min of silver deposition times, the peak associated with AuNPs was disappeared due to full coverage of AgNPs as shell material. A single sharp maximum was detected at 429 and 435 nm for the AuNP@PDOP@60AgNP and AuNP@PDOP@120AgNP NP systems, respectively. It seems that this blue-shift in the absorption maxima in these two systems is due to the higher deposition of silver ions. When the silver deposition times were increased, the size of the AgNPs was increased accordingly.

For further analysis, I also collected some TEM images to evaluate the morphology of each NP system. Some representative images were summarized in Figure 3. For the case of bare AuNPs (Figure 3a), mostly spherical NPs with an average size of $18 \mathrm{~nm}$ and monomodal size distribution was observed (Figure 2a). After $2 \mathrm{~h}$ of PDOP deposition time, I detected a conformal thin layer of PDOP having a thickness of $10 \pm 3 \mathrm{~nm}$ onto the AuNPs (Figure 2a and 3b). This conformal PDOP layer with its abundant functional groups including catechol, amine, and imine can be used in the reduction and adsorption metallic ions to fabricate core/shell NP systems. After the reduction of silver ions onto the AuNP@PDOP NP system, time-dependent core/shell NPs with different morphology was detected via TEM images (Figure 3c-e). Also, the color of the NP suspensions was dramatically due to the emergence of silver nanostructures as shell materials (see the insets in Figure 3) For all AuNP@PDOP@AgNP systems, it seems that the surface of the AuNP@PDOP NPs was fully coated with silver nanostructures. As the silver deposition times were increased, the thickness of the AgNPs was increased accordingly. The thickness of the silver shell was measured as $6 \pm 2,7 \pm 2$, and $8 \pm 3$ nm for AuNP@PDOP@30AgNP, AuNP@PDOP@60AgNP, and AuNP@PDOP@120AgNP system, respectively. I also collected some elemental mapping and the relevant EDAX spectrum of the AuNP@ PDOP@60AgNP system (Figure 4). These data showed that almost all NP systems (>95\%, by analyzing at least 100 NPs) have the core-shell morphology. Also, the presence of the gold and silver was confirmed in the EDAX spectra the core and shell material, respectively. Similar results were also detected for the other core-shell NP systems (AuNP@PDOP@30AgNP, and AuNP@PDOP@120AgNP) of the study (not shown here) [10].

In the light of UV-vis absorption spectra and TEM images, I can specify that the core-shell NP system of AuNP and AgNP was efficiently synthesized in desired morphology and size through a versatile thin layer of PDOP. 


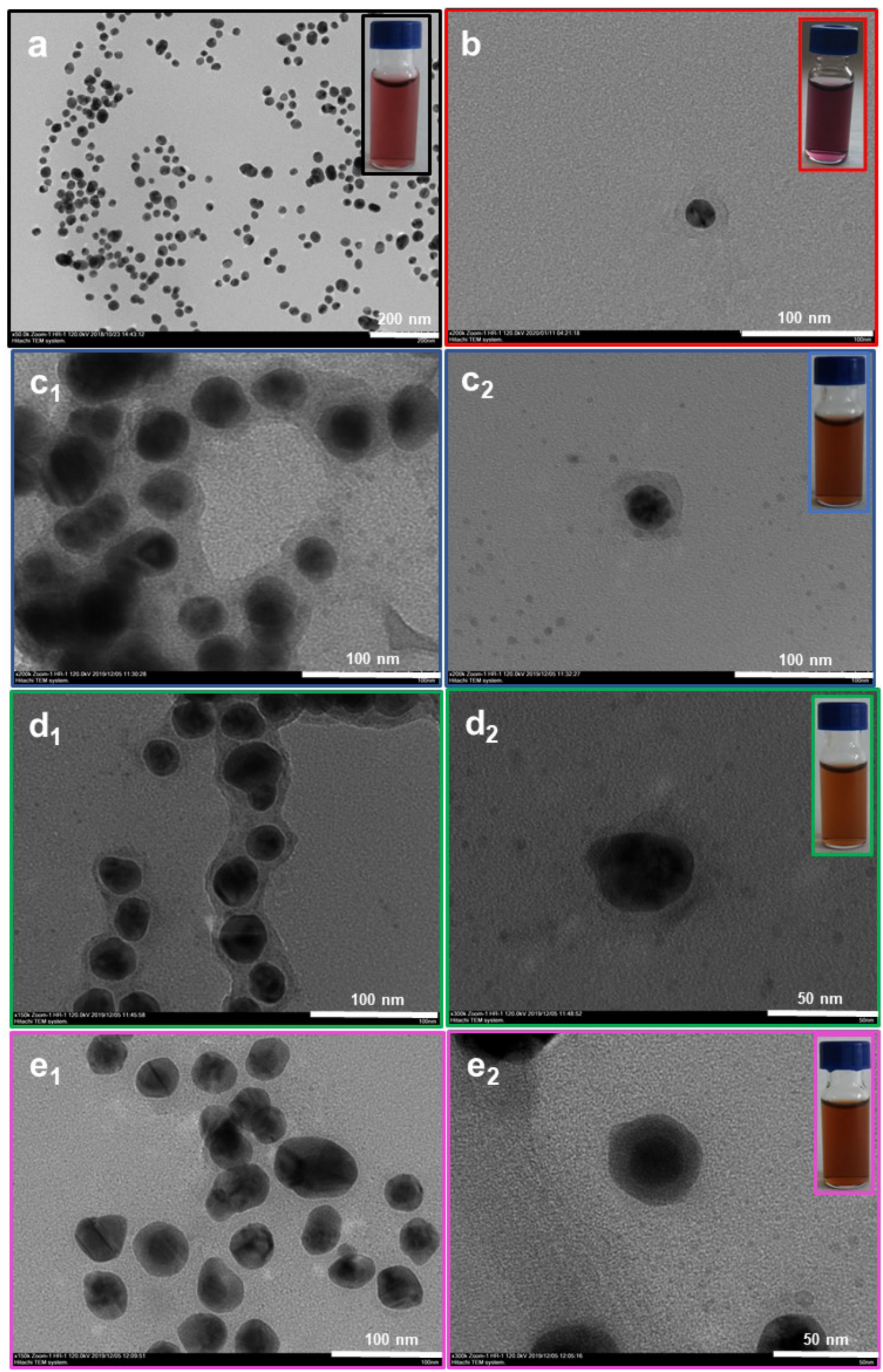

Figure 3. Representative TEM images of bare AuNPs (a), AuNP@PDOP (b), AuNP@PDOP@30AgNP (c), AuNP@PDOP@60AgNP (d), and AuNP@PDOP@120AgNP (e) at different magnifications. Insets show optic images of relevant NP systems. Insets show the optic images of the relevant NP suspensions. 


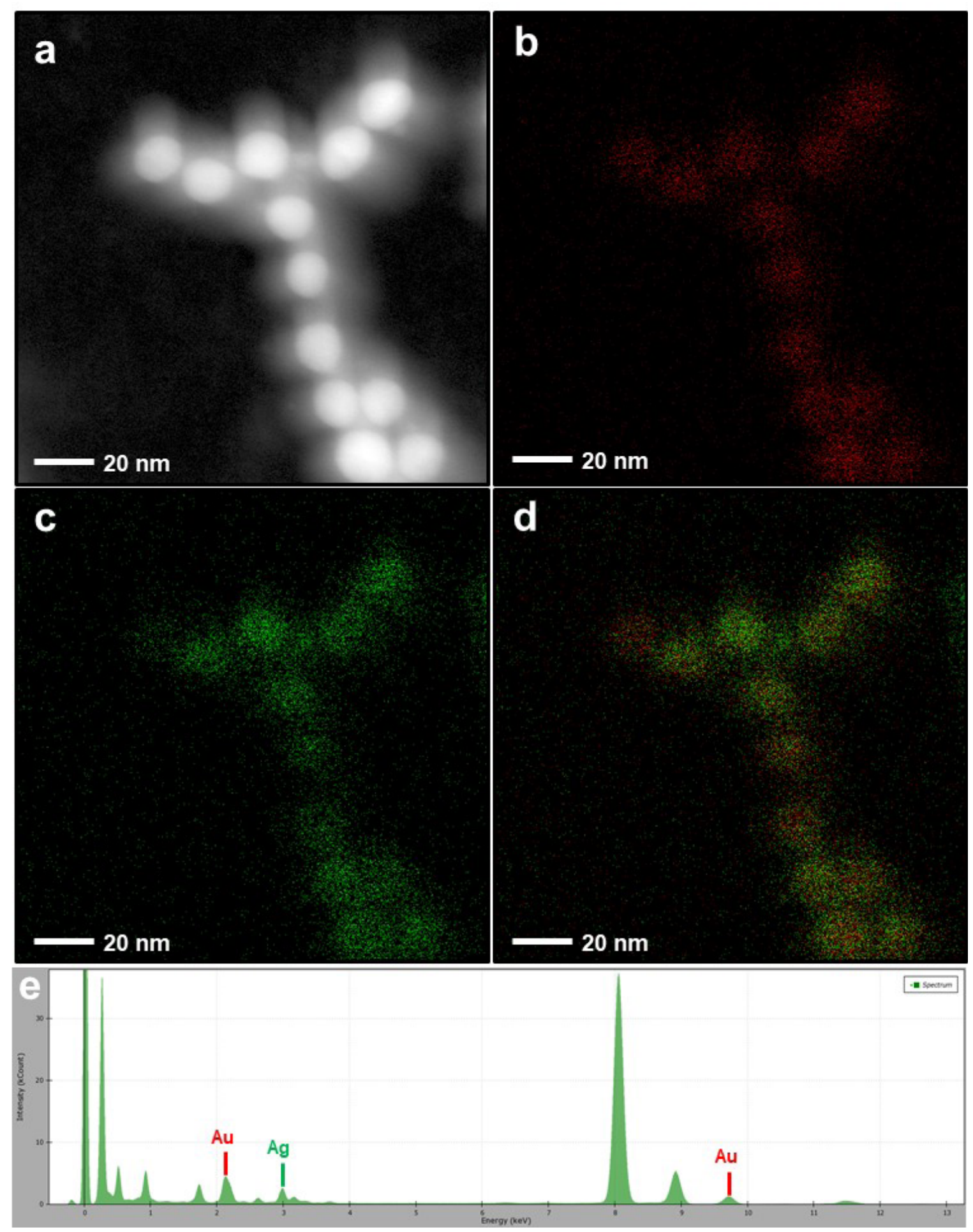

Figure 4. Elemental mapping and the relevant EDAX spectrum of the AuNP@PDOP@60AgNP system. Electron micrograph region (a), distribution of Au and (b), Ag elemental mapping (c), overlay of Au and Ag (d), and the relevant EDX spectrum (e). 

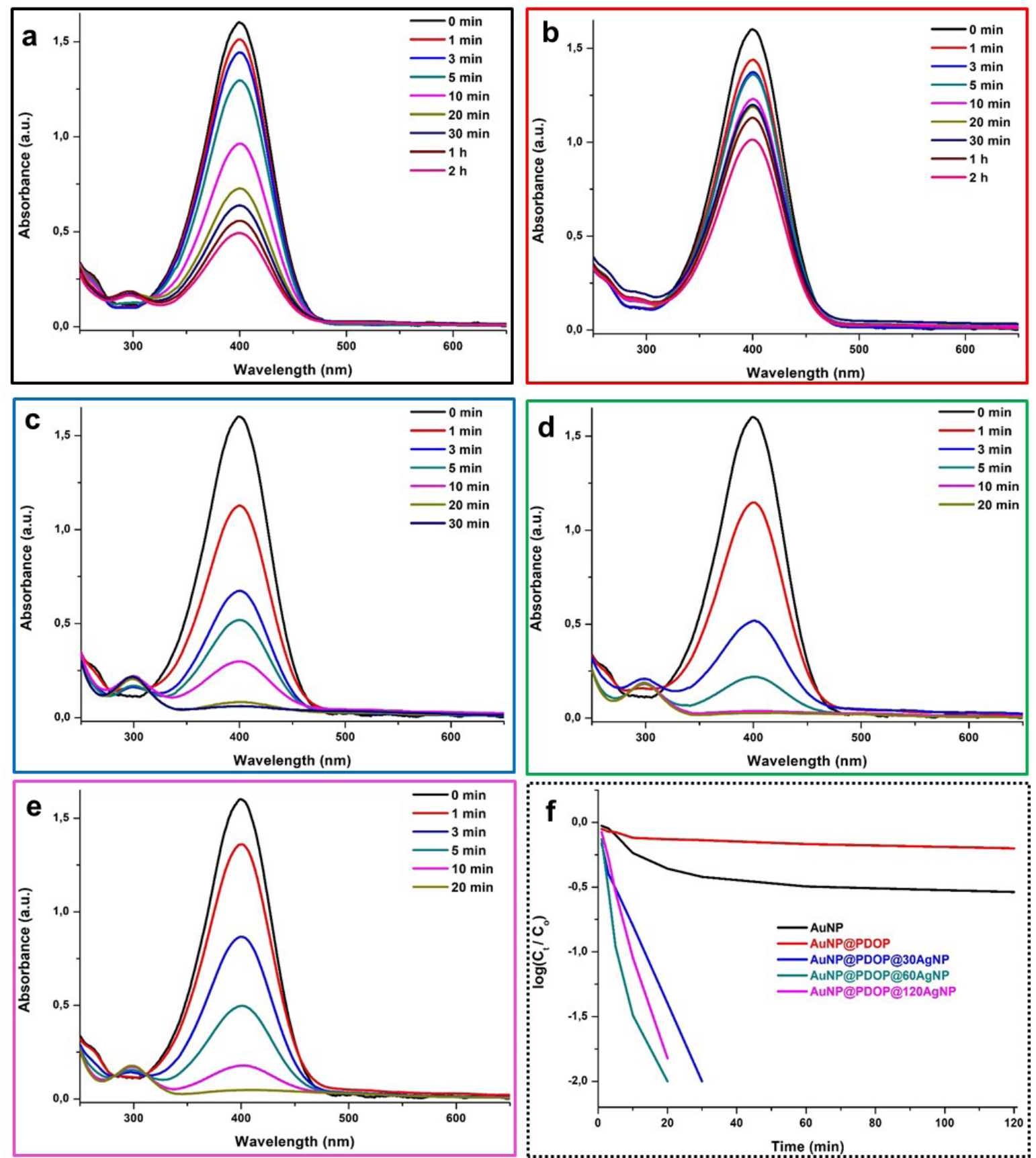

Figure 5. Catalytic activity tests of NP systems. The time-dependent UV-vis spectra for the reduction of 4-NP for bare AuNPs (a), AuNP@PDOPNPs (b), AuNP@PDOP@30AgNPs (c),AuNP@PDOP@60AgNPs (d), and AuNP@PDOP@120AgNPs as well as the relevant kinetics of the model reaction for each of the NP system. 
After efficient synthesis of each NP system, their cataIytic activities were tested in the reduction of 4-NP to 4-AP. Figure 5 summarizes the catalytic activity of the platforms through UV-vis absorption spectra and the kinetic model of the reaction. In the presence of $\mathrm{NaBH}_{4^{\prime}}$ the chemical reduction of 4-NP to 4-AP is favorable. However, the large kinetic barrier due to the potential difference of donor $\left(\mathrm{BH}_{4}{ }^{-}\right)$and acceptor (4-NP) limits the progression of the reaction $[13,16,17,19]$. The employment of metallic nanostructures facilitates the transfer of the electron from the donor to the acceptor. I used the UV-vis spectra to monitor the catalytic reduction process. Also, the progress of the reaction was observed by the naked eye. During the reaction, the yellow color due to the presence of 4-NP gradually disappeared and the colorless solution was detected in the case of absolute conversion. For the case of bare AuNPs, the partial conversion was detected even after $2 \mathrm{~h}$ of reaction time (Figure 5a). However, after PDOP deposition onto the AuNPs, the reaction rate decreased remarkably (Figure $5 b)$. This issue can be attributed to the presence of the PDOP layer. Here, the PDOP layer hindered the transfer of the 4-NP to the metallic NP surface and reduced the catalytic conversion. On the other hand, for the cases of AuNP@PDOP@AgNPs, after deposition of the silver ions onto the AuNP@PDOP NPs, the remarkable increase was detected in the catalytic activity (Figure 5c-e). The intensity of peak associated with 4-NP at $392 \mathrm{~nm}$ gradually decreased and a new peak showing the formation of 4-AP was observed at 305 nm. For all AuNP@PDOP@ AgNP systems, the complete conversion was obtained within $30 \mathrm{~min}$. Due to the low concentration of NP systems $(0.33 \mathrm{ppm})$, there was no observed absorbance band associated with their presence. From these data, it is clear that $60 \mathrm{~min}$ of the silver reduction time is the optimum value for the given experimental procedure (Figure $3 d$ ). It seems that the formation of the core-shell nanostructure of gold and silver created a synergistic effect as a catalyst. To further investigate and quantify the catalytic performances, I also performed some kinetic calculations (Figure 5f). From the kinetic evaluation of pseudo-first-order reaction, the rate constants are calculated as 0.08, 0.1, and 0.06 min $^{-1}$ for AuNP@ PDOP@30AgNPs, AuNP@PDOP@60AgNPs, and AuNP@ PDOP@120AgNPs, respectively. In comparison to our earlier reports for different metallic nanosystems, these rate values are at least ten-times higher indicating the excellent efficiency of the core-shell system as an ideal catalytic system $[13,16,17]$.

\section{Conclusion}

In the context of this study, I could efficiently synthesize bimetallic core-shell nanostructures of gold and silver by employing a thin layer of PDOP. Herein, PDOP as an interface between gold and silver nanostructures provided satisfying performance in the reduction of silver ions and stabilization of silver nanostructures onto the AuNPs. The emergence of the bimetallic core-shell nanosystem led to significant enhancement in their catalytic activity in the reduction of 4-NP to 4-AP. It was observed that silver ion reduction time has a certain effect on the catalytic activity of the AuNP@PDOP@AgNP core-shell system. This study paved the way for our prospective studies which will be on the employment of the proposed core-shell nanosystems in targetted bioimaging and sensing systems.

\section{Acknowledgment}

This work was supported by The Scientific and Technological Research Council of Turkey (TUBITAK, No: 119Z740). The authors also kindly acknowledge the East Anatolia High Technology Application and Research Center (DAYTAM) at Ataturk University for providing laboratory spaces and the characterization devices.

\section{References}

1. S. Eustis, M.A. El-Sayed, Why gold nanoparticles are more precious than pretty gold: noble metal surface plasmon resonance and its enhancement of the radiative and nonradiative properties of nanocrystals of different shapes, Chem. Soc. Rev., 35 (2006) 209-217.

2. A.T. Bell, The impact of nanoscience on heterogeneous catalysis, Science, 299 (2003) 1688-1691.

3. P. Wang, B. Huang, Y. Dai, M.-H. Whangbo, Plasmonic photocatalysts: harvesting visible light with noble metal nanoparticles, Phys. Chem. Chem. Phys., 14 (2012) 98139825.

4. R. Narayanan, M.A. El-Sayed, Catalysis with transition metal nanoparticles in colloidal solution: nanoparticle shape dependence and stability, J. Phys. Chem. B., 109 (2005) 12663-12676.

5. M.B. Gawande, A. Goswami, T. Asefa, H. Guo, A.V. Biradar, D.-L. Peng, R. Zboril, R. Varma, Core-shell nanoparticles: synthesis and applications in catalysis and electrocatalysis, Chem. Soc. Rev., 44 (2015) 7540-7590.

6. J.-F. Li, Y.-J. Zhang, S.-Y. Ding, R. Panneerselvam, Z.-Q. Tian, Core-shell nanoparticle-enhanced Raman spectroscopy, Chem. Rev., 117 (2017) 5002-5069.

7. M. Khatami, H.Q. Alijani, M.S. Nejad, R.S. Varma, Core@ shell nanoparticles: greener synthesis using natural plant products, Appl. Sci., 8 (2018) 411.

8. H. Lee, S.M. Dellatore, W.M. Miller, P.B. Messersmith, Mussel-inspired surface chemistry for multifunctional coatings, Science, 318 (2007) 426-430. [

9. Y. Liu, K. Ai, L. Lu, Polydopamine and its derivative materials: synthesis and promising applications in energy, 
environmental, and biomedical fields, Chem. Rev., 114 (2014) 5057-5115.

10. A. Yilmaz, M. Yilmaz, Bimetallic Core-Shell Nanoparticles of Gold and Silver via Bioinspired Polydopamine Layer as Surface-Enhanced Raman Spectroscopy (SERS) Platform, Nanomaterials, 10 (2020) 688

11. M. Yilmaz, E. Senlik, E. Biskin, M.S. Yavuz, U. Tamer, G. Demirel, Combining 3-D plasmonic gold nanorod arrays with colloidal nanoparticles as a versatile concept for reliable, sensitive, and selective molecular detection by SERS, Phys. Chem. Chem. Phys., 16 (2014) 5563-5570.

12. B. Nasseri, M. Yilmaz, M. Turk, I.C. Kocum, E. Piskin, Antennatype radiofrequency generator in nanoparticle-mediated hyperthermia, RSC Adv., 6 (2016) 48427-48434.

13. M. Yilmaz, G. Bakirci, H. Erdogan, U. Tamer, G. Demirel, The fabrication of plasmonic nanoparticle-containing multilayer films via a bio-inspired polydopamine coating, RSC Adv., 6 (2016) 12638-12641.

14. A. Yilmaz, The employment of a conformal polydopamine thin layer reduces the cytotoxicity of silver nanoparticles, Turk. J. Zool., 44 (2020) 126-133.
15. M.S. Akin, M. Yilmaz, E. Babur, B. Ozdemir, H. Erdogan, U. Tamer, G. Demirel, Large area uniform deposition of silver nanoparticles through bio-inspired polydopamine coating on silicon nanowire arrays for practical SERS applications, J. Mat. Chem. B., 2 (2014) 4894-4900.

16. G. Bakirci, M. Yilmaz, E. Babur, D. Ozden, G. Demirel, Understanding the effect of polydopamine coating on catalytic reduction reactions, Cat. Comm., 91 (2017) 48-52.

17. M. Yilmaz, Silver-Nanoparticle-Decorated Gold Nanorod Arrays via Bioinspired Polydopamine Coating as SurfaceEnhanced Raman Spectroscopy (SERS) Platforms, Coatings, 9 (2019) 198.

18. M. Yilmaz, 3-D and Plasmonic Nanoparticle Decorated Catalytic System via Bio-inspired Polydopamine Coating: Cigar Filter Case Study, Hacettepe J. Biol. Chem., 46 (2019) 515-521.

19. A. Gangula, R. Podila, L. Karanam, C. Janardhana, A.M. Rao, Catalytic reduction of 4-nitrophenol using biogenic gold and silver nanoparticles derived from Breynia rhamnoides, Langmuir, 27 (2011) 15268-15274. 